\title{
Algunas posiciones subjetivas frente a lo pulsional en los sueños*1
}

\section{Some subjective positions in view of the drive in dreams}

\author{
Celeste Labaronnie*2 \\ Gabriel Lombardi*3
}

Este artículo trata sobre la inserción de la pulsión en el sueño y la posición subjetiva frente al mismo. Se distinguen tres posiciones: una defensiva, otra más abierta, y una posición decidida, propia de los análisis avanzados. Se utilizan textos freudianos para situar las dos primeras y textos sobre resultados del pase para la tercera. Se concluye que el análisis permite cambiar la forma de recepción de los propios sueños, favoreciendo otras funciones, diferentes de la de ser "el guardián del dormir".

Palabras clave: Sueño, pulsión, posición, despertar

${ }^{* 1}$ Un $30 \%$ de los contenidos de este artículo se encuentran publicados en las Actas del V Congreso Internacional de Investigación de la Facultad de Psicología de la Universidad Nacional de La Plata, Argentina, en el artículo breve titulado "Algunas posiciones subjetivas frente al sueño dilucidadas por el psicoanálisis”. Año 2015. Autora: María Celeste Labaronnie. Disponible en: <http://sedici.unlp.edu.ar/handle/10915/56919>.

*2 Universidad Nacional de La Plata (La Plata, Argentina).

${ }^{* 3}$ Universidad de Buenos Aires - UBA (Buenos Aires, Argentina). 


\section{ARTIGOS}

\section{Introducción}

En este artículo, nos preponemos mostrar que las formas del soñar y del relatar un sueño nunca son ajenas a la relación que cada cual establece con el inconsciente en determinado momento de la cura, es decir, a la posición subjetiva desde la cual se le supone o no un saber, se admite o se rechaza su incidencia íntima.

Como propone Lacan (1966-1967), "el lazo de quien que habla con la verdad, no es el mismo según el punto en el que sostiene su goce". Por consiguiente, es esperable que el lazo con la verdad se vaya modificando a lo largo de un análisis, especialmente a medida que el goce en juego comienza a evidenciarse como producto de la posición subjetiva. Nos interesa señalar cómo estas modificaciones repercuten en la escena onírica.

Al inicio, comentamos un trabajo de Colette Soler con respecto al punto de inserción de la pulsión en el sueño, donde se defiende la idea de que toda producción onírica recubre lo que Freud (1911/2001b) (supo reconocer en los primeros sueños de una cura como "material patógeno" (p. 89). La presencia de este material, núcleo de toda neurosis, hace que los primeros sueños que se llevan a análisis sean una forma condensada, imposible de desenredar en ese momento, de todo lo que se desarrollará en el devenir de esa cura. Estas precisiones son ilustradas con del sueño del Hombre de los Lobos (Freud, 1918/1999).

A continuación, distinguimos tres posiciones paradigmáticas frente a ese real pulsional que el sueño envuelve:

- una posición defensiva, que recubre al máximo la inconsistencia en el saber y la correlativa presencia del objeto;

- una posición un poco más dócil, que presta atención al encadenamiento entre sueños y a la presencia de lo pulsional en la escena onírica; 
- una posición decidida, propia del análisis avanzado, donde los sueños son sede de ciertos atravesamientos y desnudan la posición fantasmática del soñante.

Por consiguiente, mostraremos que la posición subjetiva no sólo determina la forma del soñar - en aspectos como su opacidad o extensión —, sino que también permite o dificulta al soñante advertir la repetición de ciertos elementos invariantes en la escena y, en última instancia, condiciona el momento y la estructura del despertar.

\section{Metodología}

Las tres posiciones respecto al sueño que diferenciamos en este artículo no recubren exhaustivamente las posiciones singulares existentes, tan diversas como cada sujeto. En todo caso, parten de ubicar ciertas lógicas, con el propósito de marcar algunos contornos útiles para la escucha clínica.

Las dos primeras se basan esencialmente en hallazgos freudianos. Por lo tanto, a la par que en el texto comentamos algunos hechos clínicos generales, articulamos nuestro punto de vista con las observaciones de Freud, siempre esclarecedoras en estos temas.

La operación de separar esas dos posiciones como dos modos diversos de relacionarse con el material onírico es una distinción nuestra, que realizamos con fines de exposición, pues en Freud se presentan como comentarios hechos al pasar, destinados principalmente a orientar al psicoanalista respecto a lo que podrá hallar en la práctica clínica de la interpretación de los sueños. El movimiento constante entre las diversas posiciones aquí detalladas, es además evidente y deseable.

Finalmente, la tercera posición que diferenciamos, surge de las constataciones realizadas por numerosos psicoanalistas en el marco del dispositivo del pase. Las instancias que lo ponen en funcionamiento, así como los cárteles que lo estudian, originan gran número de intercambios orales y publicaciones, permitiendo que pueda hablarse actualmente de una "clínica del pase". Para nuestro trabajo, recortamos únicamente lo atinente al sueño, sus formas y los modos de recepción por parte del soñante. Nuestro material clínico, en este caso, es extraído tanto de publicaciones donde se narran los sucesos en primera persona, como de textos de comentadores, que mencionan sólo los sueños, protegiendo la identidad de los soñantes en cuestión. 


\section{ARTIGOS}

\section{Lo que el sueño envuelve}

En 1988, Colette Soler se preguntaba: “¿Hay algo en el sueño que nos asegure que la vida no es un sueño, que nos asegure que no estamos en la caverna poblada de sombras que imagina Platón?” (p. 75). Partiendo de este interrogante, la autora afirmaba que había cuestiones referidas al sueño que era necesario abordar, para decidir qué recepción debe darse a la producción onírica durante la cura.

Si bien la pregunta por el lugar de la pulsión en el sueño podría parecer paradójica - pues habitualmente se asume que el sueño pertenece pura y exclusivamente a los registros simbólico e imaginario - , Soler se atrevía a postular que Die Traumdeutung podría verse enriquecida si se lograse dar a la pulsión el lugar exacto que tiene en algunos sueños.

En primer lugar, la autora aclara que no cree que el ombligo del sueño sea ese lugar de inserción de la pulsión. El ombligo le parece un fenómeno esencialmente significante, que podría escribirse de la misma forma que el significante del Otro barrado; es el equivalente del "no hay relación sexual", pero no dice nada acerca del funcionamiento de la pulsión en ese soñante en particular. Lacan ya se había pronunciado al respecto, en su "Respuesta a una pregunta de Marcel Ritter" (1975), expresando que no creía que el ombligo del sueño fuera el punto de inserción de la pulsión en el mismo.

Mediante su pregunta por la pulsión, Soler interroga si el sueño puede dar algún acceso al ser del sujeto; es decir, ya no a su falta en ser, palpable en la mayoría de los sueños debido al funcionamiento de la metonimia, sino a una positividad. Es sabido que el sueño puede metaforizar la castración, pero con el goce en su positividad, siempre en exceso, la operación no es de sustitución.

Con estos pasos llega la autora a su propuesta central:

... me parece que hay en el sueño - no en todos, sino en algunos sueños - algo que no está desplazado ni metaforizado. (...) un foco fijo, que no es negativo como el ombligo, que no es una falta, sino que es presencia, lisa y llanamente, allí. Sin duda esto no ocurre con todos los sueños - algunos se reducen a la arquitectura significante - , pero es una potencialidad del sueño. (Soler, 1988, p. 79)

Alrededor de ese foco fijo, dice Soler, se conforma la escena del sueño; los significantes se acomodan alrededor de un punto privilegiado, como puede verse en el sueño del Hombre de los Lobos y en algunos sueños relatados por pasantes. 
Para distinguir a estos sueños de los habituales, la autora destaca la función mostrar, como opuesta a la de decir. Ese mostrar le parece una cuestión de construcción, la posibilidad de convocar, de hacer aparecer o desaparecer de improviso, el más allá o más acá de la realidad, esto es, el real que tanto la realidad como la escena del sueño velan. La mostración de la mirada, la voz, los objetos anal u oral, en sus múltiples formas oníricas, habitualmente desemboca en el despertar.

Para trazar esta separación entre sueños donde predomina el mostrar y sueños de metonimia significante, Soler propone diferenciar:

- la puesta en escena propia de los primeros, edificados alrededor de un elemento insustituible, un elemento de goce;

- la figuración, esto es, la traducción en imágenes necesaria en todo sueño.

Para la autora, la puesta en escena presupone a la figuración, pero no se reduce a ella. "La figuración es, para decirlo con exactitud, una limitación de escritura. El sueño es un jeroglífico escrito por medio de imágenes. Digamos que la figuración es del orden del alfabeto" (Soler, 1988, p. 79), y es ineludible, pues hace a la estructura de todo sueño.

La puesta en escena, en cambio, es la que permite instalar en el sueño un foco pulsional, que no admite sustitución, y alrededor del cual se construirá el tejido significante del mismo. Estas precisiones le permiten indicar que:

... detrás del sueño del Hombre de los Lobos, hay algo de real. Un real que no es puntual, que determina para siempre para el sujeto las vías particulares de su deseo y de su goce; es decir, la función de esa escena infantil. Esta determina al sujeto. No como deseante en general, deseante indeterminado, sino como tal deseante, en particular. El traumatismo freudiano está en lugar de la causa. (Soler, 1988, pp. 78-79)

Lo que, con Lacan, consideramos traumático de un modo más general, a saber, el encuentro con lalangue - es decir, con el campo del lenguaje en tanto campo del goce (Alomo, Muraro, \& Lombardi, 2013; Lacan, 19711972/2012), deja marcas que son proclives a esconderse/mostrarse en los intersticios de la escena onírica, revelando la configuración singular que han tomado para ese ser hablante. Según ya lo percibía Freud (1911/2001b), las "mociones de deseo patógenas" (p. 89) que estructuran la neurosis, suelen presentarse en los sueños de una forma bastante despojada al inicio y al final de la cura; a tal punto que los sueños "biográficos" (Freud, 1900/2001a, p. 371, n. 28) o "programáticos" (p. 354) pueden ser equiparados a "una traducción de todo el contenido de la neurosis al lenguaje del sueño" (Freud, 1911/2001b, p. 89). 


\section{ARTIGOS}

Con Lacan (1962-1963/2006a, p. 85), reconocemos en sueños como el del Hombre de los Lobos, la presencia del objeto $a$, aquello que Soler destaca como punto de inserción de la pulsión. Freud (1918/1999) ya había comentado que "el mirar atento que en el sueño se atribuye a los lobos debe más bien trasladarse a él [al soñante]" (p. 34), dándonos así una idea inicial del papel del objeto en el fantasma. Agrega, además, que el sueño suele jugar con la gramática pulsional, sugiriendo, en este caso, relaciones entre el mirar inmóvil y la fuerte movilidad, intercambiando el sujeto y el objeto, la actividad y la pasividad, el mirar y el ser mirado.

Ahora bien, cabe una ulterior consideración acerca de esta presencia: "es necesario agregar que, según Freud, esta presencia es la verdad latente de todos los sueños, precisamente en el caso de las escenas infantiles, señala que todos los sueños de un sujeto tienen un solo contenido, siempre el mismo" (Soler, 1988, p. 79).

Ahora bien, si suponemos que esta presencia es la verdad de todo sueño, o incluso su causa, cabe observar de qué modo algunos sueños la recubren del modo más acabado posible, mientras que otros se autorizan a retirar en mayor o menor medida este disfraz.

De acuerdo con la idea que prepone Lacan (1972-1973/2008b) del inconsciente como un saber-hacer con lalangue, el trabajo del sueño siempre teje con significantes una vestidura para el real en juego; en términos freudianos, podríamos decir que "lo elabora" (Freud, 1914/2001c). Ese real, hay que decirlo, tampoco podría ser mostrado en su costado informe e irrepresentable; no hay modo de aproximársele que pueda renunciar al semblante - es decir, a la hermandad inseparable entre la verdad y la apariencia (Lacan, 1971/2009). El objeto $a$ ya es, de por sí, un semblante (Lacan, 19721973/2008b, p. 112), y el sueño, con su especial estructura en imágenes, agrega otro semblante más.

Sin embargo, las diferencias entre sueños que recubren copiosamente su causa y sueños que se avienen, en cierta medida, a desnudarla, nos parece una distinción clínica, que puede trazarse tomando en cuenta la posición subjetiva del soñante en distintos momentos de la cura. 


\section{Posiciones defendidas: manifestaciones de la impotencia en la relación con los sueños}

Sabemos que la neurosis tiende a disfrazar de impotencia aquello que por estructura habita al ser hablante, a saber, la inconsistencia, la castración. Esto en el sueño suele traducirse en relatos particularmente opacos, donde el disfraz se vuelve excesivo y obstaculizador del análisis.

Freud se ocupó de esto en varias oportunidades y, en todos los casos, atribuyó el hecho a la resistencia. Sus principales observaciones sobre el tema se encuentran comprimidas en tres breves escritos: "El uso de la interpretación de los sueños en el psicoanálisis" (1911/2001b), "Observaciones sobre la teoría y práctica de la interpretación de los sueños" (1923/2000a) y "Algunas notas adicionales a la interpretación de los sueños en su conjunto" (1925/2000b).

Basándose en los hallazgos de su práctica, Freud (1911/2001b)escribe:

En ocasiones la producción onírica es tan copiosa y tan vacilante el progreso del enfermo en el entendimiento de los sueños, que el analista no puede apartar de sí la idea de que ese ofrecimiento de material no sería sino una exteriorización de la resistencia. (p. 88)

Nótese esta mención al "vacilante progreso del analizante", donde, a la vez que lleva a sesión abundantes producciones, parece desligarse del efecto que podría tener la asociación libre. Dicho de otro modo, soñar en cantidad no vale gran cosa si el soñante no es realmente conmovido por su producción o por los hallazgos asociativos.

Freud también advierte acerca de algunos pacientes que, tras presentar unos primeros sueños esclarecedores, llevan al análisis otros sumamente largos y oscuros, que desbordan las posibilidades de trabajo en una sesión. Muestra así que la extensión de los sueños, por sí misma, puede resultar un obstáculo para el trabajo analítico. Pero estas observaciones deben matizarse tomando en consideración la oportunidad del acto analítico, como veremos a continuación.

Es evidente que a veces el sueño se ofrece a una aprehensión imaginaria rápida, porque suele presentar, merced a la elaboración secundaria, una estructura discursiva similar a la narración literaria. Sin embargo, sabemos por Freud que ese aspecto del sueño es altamente engañoso, y que cada uno de los elementos oníricos debe ser tomado según su valor simbólico, sino de acuerdo con su referencia signante (Freud, 1900/2001a, 


\section{ARTIGOS}

p. 285). Por consiguiente, el aspecto narrativo - el "cuento" que el sueño pueda presentar —, no merece especial atención. No será sino aislando algunos elementos que podrá progresar el análisis - recuérdese que el vocablo proviene del griego lysis, cuyo significado es justamente disolución, descomposición de elementos.

Freud señala, entonces, excesos por cantidad — demasiados sueños por extensión - sueños demasiado largos y cargados — y por opacidad sueños oscuros y confusos, que de algún modo se sustraen a la posibilidad de asociación libre.

Finalmente, señala también una forma muy particular de resistencia:

En el caso de una presión de resistencia extremadamente alta, ocurre el fenómeno de que la asociación del soñante se extiende a lo ancho, en vez de ir hacia lo profundo. En lugar de las deseadas asociaciones sobre el sueño relatado, salen a la luz nuevos fragmentos oníricos, que a su vez quedan faltos de asociación. (Freud, 1923/2000a, p. 112)

A nuestro parecer, este obstáculo es el más frecuente en los sueños que presentan una estructura narrativa sobre-elaborada. Habitualmente, los sueños bien encadenados, lógicos y sin lagunas presentan un desafío mayor al trabajo analítico, puesto que el acto del analista apunta justamente a desarmar la ficción que el inconsciente construye, desarmarla hasta extraer su axioma mínimo, donde el objeto encarna el ser del sujeto, comandando tanto su deseo como su manera singular de padecer.

$\mathrm{Si}$ el soñante es tomado por la pregnancia imaginaria del relato, se vuelve más difícil introducir cortes en los significantes o preguntas que apunten a desligar los elementos del sueño de su contexto onírico. No obstante, una técnica diestra, dice Freud, permite perfectamente sortear estos obstáculos. Él mismo insinúa que puede ser la prisa del analista por hacer señalamientos la que despierte esta resistencia que, posteriormente, colaborará con la producción de sueños inabordables. Es por eso que invita al practicante renunciar a toda interpretación "completa" de un sueño y a tener especial cautela con las primeras producciones oníricas que aparecen en una cura, puesto que "un sueño así se edifica a menudo sobre el material patógeno del caso en su conjunto, material del que aún no tienen noticia ni médico ni paciente" (Freud, 1911/2001b, p. 89).

Como vemos, Freud coligió tempranamente que la causa que el sueño recubre irá develándose con el progreso de la cura. Acompañando el ritmo de cada analizante, el analista "puede hacer la experiencia de que un sueño al comienzo incomprensible deviene transparente en la próxima sesión, después 
que se logró eliminar una resistencia del soñante por medio de un señalamiento feliz" (Freud, 1925/2000b, p. 131). De hecho, lo que se presenta aparentemente como una resistencia, suele encerrar el material discursivo al que se debe prestar atención (Lombardi, 1991). Los sueños, por lo tanto, resultan útiles para producir el acto analítico aún cuando se presentan en su modalidad más defendida.

Podría decirse que, con Lacan, los analistas hemos aprendido a realizar sobre los sueños señalamientos mínimos, ya sea extraer del relato un significante, un sonido, o apuntar hacia un elemento del sueño que condensa un valor pulsional único. A su vez, es evidente que el progreso de la cura incide también en el modo de presentación de los sueños, llevándolos hasta el extremo de producir sobre el soñante un efecto de interpretación solidario del corte, es decir, no ya un efecto de verdad entre otros, sino una destitución que agujeree el peso de la novela neurótica. Abordaremos este tema más adelante, al considerar el tercer tipo de posición frente al sueño.

\section{Un tipo de docilidad frente al sueño: las continued stories}

Para pasar a considerar el segundo modo de relación con los propios sueños que hemos elegido diferenciar, nos interesa otro hallazgo de Freud: el caso en que una serie de sueños viene a encadenarse, a la manera de una continued story (Freud, 1923/2000a, p. 113).

Al respecto, Freud explica que en algunos análisis, o en algunos tramos de los mismos, los sueños son capaces de anudarse unos con otros en la diacronía, tomando como centro un elemento que en el sueño anterior se rozaba de pasada y así sucesivamente. Freud remarca que se establece de ese modo una separación entre la vida onírica y la de vigilia, puesto que el trabajo soñante se avoca a retomar un elemento que solamente ha cobrado vida en la escena onírica y que va sufriendo diversas transformaciones según los sueños se van encadenando.

Por nuestra parte, hemos comprobado este modo de encadenamiento entre sueños en pacientes cuya consulta se presenta por la vía de la angustia. En algunos de esos casos, ha surgido durante las entrevistas preliminares la mención a sueños recurrentes, a veces desde la infancia. Una vez alojados en el dispositivo, estos sueños comienzan a enlazarse con otros nuevos, que transforman uno o varios elementos de la escena onírica, conservando siempre un punto de fijeza, que no desaparece, pero sí se modifica y se integra 


\section{ARTIGOS}

en nuevas relaciones con los demás. Por ejemplo, un mar inabarcable, que amenaza con ahogar, después de numerosas transformaciones y a lo largo de cierto tiempo de análisis, se presenta como un pequeño charco entre montañas o el lecho del que un barco pesquero extrae interesantes ejemplares.

En otras ocasiones, sin que el consultante recuerde sueños previos a la consulta, el trabajo de análisis produce a veces la concatenación entre un primer producto onírico y una serie que adviene posteriormente y va transformando los elementos de diversas maneras. Tal es el caso de unas pesadillas donde se huye de una oscuridad amenazante, que pasa a ser iluminada de forma intermitente en sucesivos sueños, llevando al soñante a precipitarse dentro de ella en un sueño cargado de valentía.

En todos los casos, cabe señalar que otros sueños, sin relación manifiesta con la continued story, suceden durante ese tiempo de análisis y aportan sus efectos; pero son los analizantes mismos quienes resaltan la aparición del elemento onírico repetitivo, que bien podría considerarse una representación de lo que venimos llamando, con Freud, "material patógeno". Los ejemplo del mar y de la oscuridad, que mencionábamos, muestran sin duda al goce de manera difusa, aún no recortada en la forma de un objeto causa de deseo. Pero es claro que el análisis va en esa dirección.

Lo más interesante que esta sucesión de sueños aporta a la cura es que permite al analizante dejarse tomar por ese saber tan particular que cifra solo, donde la inconsistencia del sentido es palpable por todos lados. Esta separación entre la vida onírica y la de vigilia, señalada por Freud, permite destacar especialmente efectos que no se deben a ningún tipo de insight o de reconocimiento consciente, sino a la redistribución de goce que acompaña a este trabajo de cifrado y a su despliegue en transferencia. Es lo que permite que una analizante diga "esta vez yo no estaba sumergida en el mar, sino que nadaba" y su alivio sea notorio en esa misma sesión, mientras que el goce redistribuido inaugura algunos cambios en su vida cotidiana.

Para delimitar conceptualmente la vía por la que procede el trabajo analítico, cabría diferenciar entre "tomar el deseo a la letra" (Lacan, 1958/2005, p. 600), y leer "entre líneas". En el segundo caso, lo que se pretende es una hermenéutica, siempre tentada de buscar los eventos de la realidad a los cuales aludiría el sueño. En el primer caso, en cambio, prevalece el plegarse a los significantes en juego, que permite al analista incauto conservar la sensibilidad que conviene para los efectos sonoros, con sus equívocos, resonancias y ecos en el cuerpo. De este modo, el objeto causa se va recortando. 
A nuestro criterio, esta distinción podría valer tanto para el proceder del analista como del analizante. Trabajar con los significantes implica tomarlos en la superficie del discurso, atenerse a la manipulación del cifrado mismo. Para ello se requiere distanciarse de la ilusión de que un sueño vale por lo que quiere decir y, antes bien, reconocer que vale por su cualidad de cifrado de goce, por su juego con lalangue.

Es así que la "separación de la vida onírica respecto de la de vigilia" que señala Freud (1923/2000a, p. 113), no requiere de una reducción, que aplaste lo inarticulable del deseo bajo una forma cualquiera de la demanda (Lombardi, 1991). Antes bien, la escucha analítica debe orientarse por lo que la escena onírica retoma, pues allí se sitúa el automaton que delinea el padecimiento, y por lo que ésta modifica, pues por esta vía se habilita la posibilidad de variación y, en definitiva, de movimiento deseante.

\section{El análisis avanzado: una posición decidida frente a los sueños}

Como decíamos anteriormente, el devenir de la cura va modificando la posición subjetiva y, correlativamente, la forma de los sueños, esto es, la dosis de disfraz necesaria en cada momento para que el sueño pueda ser tolerado por la censura. Cuando el sueño llega demasiado lejos, cuando se atreve a poner en escena y desnudar el objeto causa de deseo y goce, la solución habitual es despertar.

Para el caso del Hombre de los Lobos y para los ejemplos breves que aporta Soler en el texto mencionado, esta es la regla: algo aparece de improviso y el despertar corta la escena, para poder continuar soñando en la escena de la realidad. Soler (1988) comenta:

Así, una joven sueña: "Me doy vuelta y veo de repente, sobre la pared, el lugar más claro dejado por la ausencia de un cuadro familiar". Sobresalto del despertar. O también, bruscamente, el sujeto se ve mirado por un ramo de claveles inmóviles. (p. 80)

Ahora bien, ¿qué posición toma el soñante frente a ese real que el sueño presenta con tan poco disfraz? ¿Qué actitud sobreviene tras el despertar?

La clínica del fin de análisis y del pase ha permitido recabar numerosos ejemplos donde el analizante, tomando una posición decidida frente a lo pulsional que el sueño muestra, no mira hacia otro lado. 


\section{ARTIGOS}

Cora Aguerre (2011), Miembro del Foro Lacaniano de Valencia, ha comentado este punto en su testimonio, haciendo especial hincapié en la revuelta que le produjo el encuentro onírico con el objeto causa y en cómo se debatió hasta tomar posición:

En el sueño estoy en un parque infantil, en un día de sol, con una sensación de liviandad agradable, hay un tubo y me acerco a él, y veo al fondo una rata. Veo la mirada de la rata y despierto. El horror es tal que durante un tiempo no puedo ni pensar pero sin embargo sé que hay allí algo fundamental que me atañe. La sensación de rechazo es muy fuerte y se manifiesta en el cuerpo como repulsa. La rata parece dormida pero mira a través de un ojo. Representa lo pulsional en juego. Aparece un goce que está en juego desde la infancia. Durante mucho tiempo había creído que era el Otro que me metía en los líos y enredos, que me decía de más, que me usaba como confidente, pero en el sueño lo que aparece no es lo que ha venido del Otro sino lo propio. Está en juego la curiosidad, el interesarme por lo que por los demás es desechado, por las miserias. Aparece la mirada puesta en juego, miro y veo el otro lado de mi ser de sujeto, el reverso de cómo he sido nombrada. (pp. 42-43)

Vemos cómo la analizante en cuestión se debate entre tomar en consideración lo que el sueño muestra, o bien desconocerlo. Finalmente, decide recoger lo que allí le atañe. Podríamos decir que se aviene a lo que Freud (1925/2000b) 1lamó "la responsabilidad moral por el contenido de los sueños” (p. 133). Es una toma de posición.

Esta posición, que se afianza al final de la cura, ha sido constatada también por otras escuelas que practican el pase. Respecto a los sueños, los hallazgos son coincidentes.

Mariel Alderete de Weskamp (1999/2006), de la Escuela Freudiana de Buenos Aires, refiere: "al terminar mi análisis, los sueños continuaron permanentemente. Cada tanto un sueño me indicaba tomar una decisión" (p. 64). A su vez, ella subraya una interesante cualidad de esos sueños, que nos interesa oponer a la constatación de Freud de que la resistencia podía volverlos extremadanamente copiosos, largos y oscuros. Alderete expresa: "en ese análisis adquirí una gran confianza en el hacer del inconsciente, de manera que los sueños comenzaron a 'decir' cada vez más, dejando transparentar el deseo en vez de presentarse como enigmas para su interpretación" (p. 55). Este decir, que con Lacan entendemos no sólo como enunciación, sino además como aquello que porta el exceso gozoso de lalangue, aparece especialmente destacado allí donde el soñante se vincula con su producción onírica de un modo mediado por la castración. La lectura de este testimonio permite 
constatar que los sueños en cuestión corresponden a la función mostrativa, a un decir que es, en definitiva, un mostrar el costado pulsional en juego.

La faz enigmática del sueño se ha reducido, la función mostrar comanda, durante un tiempo, el trabajo onírico. Esta forma tan magra del soñar suele suceder en los últimos momentos de la cura y se retoma, según muchos autores, durante el pase. Pasado cierto tiempo, el sueño parece volver a su modalidad habitual. Entre ambos momentos, algunos analistas también testimonian sobre un período donde no recuerdan ningún sueño.

Al igual que Cora Aguerre y Mariel Alderete, Fabián Naparstek (2005), miembro de la Escuela de la Orientación Lacaniana, ha relatado un sueño donde también se destaca la posición subjetiva frente a lo pulsional desnudado por el análisis. El soñante, de segundo nombre Abraham, se encuentra en la escena onírica a punto de matar a su primogénito, a pedido de la voz de Dios, como en el relato bíblico. Se despierta de inmediato, aunque sin angustia, y es justamente la ausencia de angustia lo que lo lleva a interrogarse: “¿bajo qué lógica soñaba eso?” (p. 53). Esta presentificación de la voz, en su cara obscena y feroz, provoca una separación entre la angustia y la novela neurótica. "Se desanuda la angustia de lo religioso, se separa el objeto y el nombre propio se vacía de sentido", explica (p. 53). Pero estas operaciones no se produjeron sin que él volviese sobre su sueño, para preguntarse por lo que allí le concernía. Este detalle, al igual que en el testimonio de Cora Aguerre, nos permite enfatizar la posición subjetiva decidida respecto al contenido de los propios sueños. Además, ilustra el modo en que el sueño logra por sí mismo producir una interpretación destituyente.

\section{Otros efectos de una posición decidida: variaciones del despertar}

En este recorrido, que nos lleva desde las formas de presentación de sueños más defendidas, hasta otras que se avienen a desnudar su causa, podríamos destacar aún otro rasgo: ¿qué sucede si en el punto de angustia no sobreviene el despertar?

Esta pregunta también merece una consideración desde la óptica de la posición subjetiva del soñante. Los desarrollos freudianos permitieron a Lacan (1969-1970/2006b) aseverar que "sólo despertamos para seguir soñando" (p. 60), cuando la escena de la realidad promete más adormecimiento que la onírica. 


\section{ARTIGOS}

Justamente por eso, señaló que el análisis está hecho para despertar al sujeto que se ha fiado del sopor del fantasma (Lacan, 1988). Por lo tanto, y por paradojal que parezca, seguir soñando puede ser, en algunos casos, un modo de no evadir el despertar. Nos referimos a los sueños cuya continuación implica un atravesamiento.

Dirijamos, en primer lugar, nuestra atención hacia el sueño de la inyección de Irma, sobre el cual Erikson (1954/1973) fue el primero en poner los puntos sobre las íes, en lo que a la posición subjetiva del soñante concierne. Cuando el sueño pone en escena el interior de una garganta llena de escaras, se produce el encuentro con un real pulsional que Freud no evade. Lacan (1954-1955/2008a) lo comentó en su seminario:

Es un descubrimiento horrible: la carne que jamás se ve (...), la carne sufriente, informe, cuya forma por sí misma provoca angustia. (...) última revelación del eres esto (...). A esta revelación (...) llega Freud en la cumbre de su necesidad de ver, de saber (...).

Erikson efectúa aquí una observación excelente, tengo que reconocerlo: normalmente, un sueño que desemboca en algo así debe provocar el despertar. ¿Por qué no despierta Freud? Porque tiene agallas.

Estoy de acuerdo: tiene agallas. (pp. 235-236)

Entonces, Freud soñante avanza más allá de la visión horrorosa del interior de la carne, ¿y qué encuentra? Encuentra la disolución yoica más palmaria, el desarmado, pieza por pieza, del precipitado de identificaciones que sostienen la ilusoria unidad yoica. Es para Lacan una confirmación exquisita del saber sin sujeto que caracteriza al inconsciente, especialmente en su vertiente real. Para Lacan, el núcleo del descubrimiento freudiano fue siempre la destitución del yo en pos del saber inconsciente, y en este sueño ese acontecimiento es palpable. Freud, empujado por su deseo de saber, acude a una visión de lo imposible, el real que le concierne, localizado allí donde él enfermará unos años más tarde.

Entonces, ¿puede el sueño ser la sede de una destitución del sujeto tal que, confrontado con su ser de objeto, el soñante no despierte sino que siga adelante? La respuesta es afirmativa, los testimonios de pase también lo han mostrado.

A este respecto, Serge Cottet (2009) ha señalado que se podría poner en relación el progreso de la cura con la posibilidad que tiene el soñante de continuar su sueño más allá del punto de angustia. Como ejemplo, cita un sueño de una pasante, más bien pesadillezco, donde la soñante caía, era reducida a papilla y corría el riesgo de ser engullida por el Otro, escapando 
finalmente de tal destino. Cottet dirá que es por dicho sueño, que la analizante accede a la posición masoquista que allí se revela.

Por nuestra parte, consideramos que cualquier estudio que tome al sueño como objeto específico de interrogación, no debe ignorar que los mismos efectos pueden suceder por otras vías que la onírica, que en definitiva no es la única forma de producción del inconsciente, ni hay razones para privilegiarla. ${ }^{1}$ Estudiar lo que distintos soñantes han testimoniado no tiene por qué conducirnos a enarbolar fórmulas, categorías o hechos universales. Se trata, en cambio, de observar lo que algunos sueños tienen de revelador acerca de los movimientos de la cura.

Si nos cernimos al sueño de Freud, vemos que el atravesamiento de la visión horrorosa lo conduce, además de a la disolución yoica, a la letra desamarrada de su sentido: la fórmula de la trimetilamina, que aparece escrita en gruesos caracteres.

En este mismo sentido, Samuel Basz (2012) comenta: "El sueño que interesa en el fin de análisis es aquel en el que el soñante se permite atravesar el inconsciente transferencial $\left(\mathrm{S}_{1}-\mathrm{S}_{2}\right)$. Atravesamiento que es condición para poder leer la letra $\left(\mathrm{S}_{1}\right)$, aislada de toda cadena significante, como causa del sueño" (p. 100). En el caso de Freud, ni siquiera se trata de un sueño que podamos calificar como "de fin de análisis", aunque sí puede decirse que Freud se encontraba en un momento crucial de despegue y de invención. En este sueño, la función de la letra es señalada magistralmente.

Por otro lado, la idea de Basz coincide con la de Soler en el punto en el que ambos retoman las formas de presentación de lo real como causa del sueño. Soler dirá que, desde Freud, es posible reconocer el deseo inconsciente, indestructible, infantil del sueño - que no será articulable en el juego significante, porque lo excede - , como la causa que lo soporta y motoriza. Basz apunta en la misma dirección cuando sostiene que "ese núcleo que causa el despertar, es también la causa del soñar" (p. 97). Esto le permite entrever que la mayoría de los sueños evaden su causa, ya que, por el contrario, trabajan para velarla. Pero hay sueños que admiten una puesta en escena de la causa real del goce del cifrado; ya sea - podemos decir ahora - en su forma de objeto $a$ o de letra.

Si tomamos como modelo el sueño de Freud, tendríamos allí un primer encuentro con lo real en la forma del objeto $a$ - en este caso, coincidente

${ }^{1}$ De hecho, Colette Soler (2013) ha destacado al lapsus como fruto privilegiado del inconsciente real, por encarnar con facilidad el agujero en el saber, cosa que el sueño no puede más que mostrar de manera imaginaria. 


\section{ARTIGOS}

con lo que Lacan (1962-1963/2006a) teoriza como parte del objeto oral, incluyendo labios, lengua, dientes y el vacío de la succión - y un segundo encuentro con otra forma de lo real: la letra. Estos dos momentos son lo que Lacan (1954-55/2008a) traduce como dos finales del sueño. Y no es casual que en el sueño de la inyección de Irma, el segundo hallazgo se obtenga una vez atravesado el primero.

Veamos ahora otra observación de Basz (2012), atinente a los testimonios:

En algunos testimonios de pase puede seguirse el camino que sitúa lo real del sueño como causa. Aunque esto no sea manifiestamente descripto en el testimonio, puede seguirse el camino lógico que indica que parte de lo significable en un sueño indica el objeto $a$ en juego como núcleo elaborable de lo real que causa el sueño. (...) Causa del sueño que no hay que confundir con el sentido más general del mismo como realización de deseo, ni con su función de guardián del dormir. (pp. 98-99)

Como vemos, al igual que Soler, él diferencia los sueños usuales de aquellos que revelan su causa. En ellos se accede a un pasaje que no es habitual en los sueños cotidianos.

Dentro de esta categoría de sueños, hemos distinguido aquellos donde el soñante despierta, de aquellos donde se continúa soñando. No obstante, no consideramos que deba separárselos, como si se tratase de fenómenos diferentes; menos aún erigir el atravesamiento onírico como una suerte de ideal clínico ligado al sueño.

Cuando se trata del sueño, lo central, a nuestro criterio, es la posición del soñante; esto es, la relación que mantiene, en determinado momento, con el real que puede presentarse agujereando la escena onírica. Por lo tanto, la posición subjetiva es determinante al momento de dar una textura más o menos espesa al tejido onírico, encargado de velar el real pulsional que habita en cada ser hablante, así como también será determinante de lo que cada cual haga con sus sueños.

\section{Consideraciones finales}

Funciones del sueño

A partir de los desarrollos hasta aquí reseñados, podemos dejar mínimamente planteada una tensión entre argumentos. 
Sabemos, desde Freud, que la función principal del sueño es la de ser guardián del dormir. En "Los límites de la interpretabilidad", llegó a escribir que "los sueños de los cuales uno no sabe decir nada tras despertar son los que mejor han desempeñado su función" (Freud, 1925/2000b, p. 129).

Ahora bien, a la luz de los numerosos testimonios de pase que han sido publicados hasta la actualidad, donde el papel conferido a los sueños es central y permite apreciar un lazo con lo onírico - y con lo inconsciente en general, por supuesto - tributario de la destitución subjetiva, ¿consideramos todavía que los sueños de los cuales uno no sabe decir nada tras despertar son los que mejor han desempeñado su función?

La experiencia parece indicar que, en ciertos momentos del análisis, el sueño desempeña otra función que la de proteger el dormir. Esto ha llevado a que algunos autores (Brousse, 1997; Cottet, 2000; Mazzuca, 2011; Yacoi, 2002,2012 ) enfaticen la función interpretativa que adquieren los sueños al final del análisis. Como hemos destacado, es la posición subjetiva del soñante la que puede mostrarse más o menos permeable a lo que el sueño muestra y recubre, en un mismo movimiento. Extraer de allí algunas consecuencias, será para cada uno una toma de posición.

En este sentido, tenemos el ejemplo de Lacan mismo, quien durante una conferencia en Saint-Anne, relataba un suceso personal y su posición al respecto. A nuestro criterio, muestra cómo la destitución subjetiva permite dar un lugar nuevo al decir inconsciente:

He hablado del despertar. Justamente hace poco soñé que el despertador sonaba. Freud dice que se sueña con el despertador cuando uno no quiere de ningún modo despertarse. [Pero] que alucine en mi sueño que el despertador suena, lo considero como una buena señal, ya que, contrariamente a lo que dice Freud, en mi caso yo me despierto. Al menos eso fue lo que me sucedió. (Lacan, 1978)

\section{Consideraciones clínicas}

¿Qué utilidad clínica tiene el estudio de estos detalles del trabajo onírico sobre el final de la cura? ¿Puede servir para sensibilizar la escucha respecto a lo real como causa del sueño?

Según la manera en que los pacientes se pronuncian, dice Cottet (2009), uno puede percibir si siguen fascinados por el sentido inconsciente o, por el contrario, por el agujero. Este hecho lo conduce, entonces, a una 


\section{ARTIGOS}

consideración sobre el desgaste que se va produciendo en la cura respecto al goce de descifrar. Esta misma cuestión aborda Colette Soler (2013) en Lacan, lo inconciente reinventado, donde examina el costado terminable y el interminable del análisis, preguntándose especialmente por la satisfacción específica que permite la caída de los amores con la verdad.

En lo que respecta a los sueños, podemos decir que este desgaste del goce de descifrar no sucede sin la participación del analista. "Hay un saber hacer con los sueños que es distinto a interpretarlos", dice Basz (2012), "se trata fundamentalmente de situar en acto lo real como causa y la consecuente captación de un estallido inédito del estatuto del Otro", afirma (p. 101). Esto en lo que concierne a los sueños, a cómo trabajarlos en análisis, pero por supuesto que el acto analítico en general, esté vinculado a algún sueño o no, es el que va propiciando al avance de la cura. En todo caso, los sueños - o mejor dicho, la forma del soñar — va acompañando esos avances.

Soler (1988), por su parte, también ha ligado su pregunta por la pulsión en el sueño con ciertos interrogantes clínicos:

¿Existe una inserción de la pulsión a nivel del sueño? ¿Una inserción de lo que, en la pulsión es goce? Creo que esta pregunta es esencial para determinar la respuesta que conviene dar al sueño en la dialéctica de la cura, aquello a lo que, después de todo, el analista se ve confrontado cada día. (p. 75)

En su conclusión, señalaba que el sueño, que habitualmente trabaja para plantear la pregunta del sujeto, bien puede a veces incluir en él una respuesta, señalando el objeto causa de deseo y de goce.

¿Pero qué función tiene esto para la cura? Ya he dicho, es cuestión de tratar al sueño-metáfora como invitación a la metonimia. En cuanto a la inserción de la pulsión, en efecto, el paciente no está ahí para gozar, aunque fuera en sueños. (...) Está ahí para decir lo que se puede decir de su ser de goce. Se trata entonces, ahí también, de despertarlo del sueño, sin que olvide lo que en el sueño despierta. (p. 81)

De aquí extraemos dos indicaciones. Por un lado, que no se olvide lo que en el sueño despierta valdría como indicación de no adormecer con palabras lo que el sueño ha logrado mostrar con cierta crudeza. Por otro lado, y esto ya para el caso del sueño ordinario, invitar a la metonimia, a la asociación, porque el paseo por los hallazgos de la asociación libre nunca se cierra - o al menos el analista no debe cerrarlo - sobre un sentido unívoco, y en su expansión de sentidos múltiples, apunta también al sinsentido, a la vacuidad del saber elucubrado, pues no concluye. Esto conduce a un agotamiento del 
trabajo analizante que, ayudado por el corte, comienza a recortarse sobre sentidos cada vez más reducidos, hasta llegar a "decir lo que se puede decir de su ser de goce", que no es mucho, pero marca una diferencia.

\section{Referencias}

Aguerre, C. (2011). Fin de análisis, pase y Escuela. Wunsch, 10, 40-44.

Alderete de Weskamp, M. (2006). Testimonio de pase. In A. Casalla et al. (Eds.), La experiencia del pase (Vol. 2, pp. 53-71). Buenos Aires: EFBA. (Trabajo original publicado en 1999).

Alomo, M.; Muraro, V., \& Lombardi, G. (2013). Tique y trauma: el encuentro electivo con lo real de lalengua. Anuario de investigaciones, 20, 43-50.

Basz, S. (2012). Respecto de los sueños, hay causa. In L. Ávola, A. Cucagna, \& A. Yacoi (Eds.), Brisas clínicas: sueño y final de análisis (pp. 97-103). Buenos Aires: Grama.

Brousse, M.-H. (1997). Algunas observaciones sobre la interpretación a partir del Cartel del Pase. In N. Alvarez, P. P. Casalins, L. Michanie, A. M. Rubistein, \& F. Vitale (Eds.), Enseñanzas del pase (pp. 21-39). Buenos Aires: Ediciones Publikar.

Cottet, S. (2000). Maître de l'interpretation ou gardien du sommeil. L'essai. Revue Clinique Annuelle, 97-100.

Cottet, S. (2009). Du rêve au symptôme. La lettre mensuelle, 278, 13-16.

Erikson, E. (1973). Los sueños de Sigmund Freud interpretados. Buenos Aires: Hormé. (Trabalho original publicado en 1954).

Freud, S. (1999). De la historia de una neurosis infantil. In Obras Completas (J. L. Etcheverry, trad., Vol. 17). Buenos Aires: Amorrortu. (Trabajo original publicado en 1918).

Freud, S. (2000a). Observaciones sobre la teoría y práctica de la interpretación de los sueños. In Obras Completas (J. L. Etcheverry, trad., Vol. 19). Buenos Aires: Amorrortu. (Trabajo original publicado en 1923).

Freud, S. (2000b). Algunas notas adicionales a la interpretación de los sueños en su conjunto. In Obras Completas (J. L. Etcheverry, trad., Vol. 19). Buenos Aires: Amorrortu. (Trabajo original publicado en 1925).

Freud, S. (2001a). La interpretación de los sueños. In Obras Completas (J. L. Etcheverry, trad., Vols. 4-5). Buenos Aires: Amorrortu. (Trabajo original publicado en 1900).

Freud, S. (2001b). El uso de la interpretación de los sueños en el psicoanálisis. In Obras Completas (J. L. Etcheverry, trad., Vol. 12). Buenos Aires: Amorrortu. (Trabajo original publicado en 1911). 


\section{ARTIGOS}

Freud, S. (2001c) Recordar, repetir y reelaborar. In S. Freud, Obras Completas (J. L. Etcheverry, trad., Vol. 12). Buenos Aires: Amorrortu. (Trabajo original publicado en 1914).

Lacan, J. (1966-1967). La lógica del fantasma. In El seminario. Libro 14. Manuscrito inédito, Escuela Freudiana de Buenos Aires, Ciudad Autónoma de Buenos Aires, Argentina.

Lacan, J. (1975). Respuesta de Jacques Lacan a una pregunta de Marcel Ritter. Inédito. Recuperado de en http://www.con-versiones.com.ar/nota0598.htm

Lacan, J. (1978). El sueño de Aristóteles. Inédito. Recuperado de: HYPERLINK $<$ http://elpsicoanalistalector.blogspot.com.ar/2012/09/jacques-lacan-el-sueno-dearistoteles.html $>$. $<$ http://elpsicoanalistalector.blogspot.com.ar/2012/09/jacqueslacan-el-sueno-de-aristoteles.html $>$.

Lacan, J. (1988). Reseña con interpolaciones del seminario de la ética. In Reseñas de enseñanza (3-23). Buenos Aires: Manantial. (Trabajo original no fechado).

Lacan, J. (2005). La dirección de la cura y los principios de su poder. In Escritos 2. Buenos Aires: Siglo XXI. (Trabajo original publicado en 1958).

Lacan, J. (2006a). El seminario. Libro 10. La angustia. Buenos Aires: Paidós. (Trabajo original publicado en 1962-1963).

Lacan, J. (2006b). El seminario. Libro 17. El reverso del psicoanálisis. Buenos Aires: Paidós. (Trabajo original publicado en 1969-1970).

Lacan, J. (2008a). El seminario. Libro 2. El Yo en la teoría de Freud y en la técnica psicoanalítica. Buenos Aires: Paidós. (Trabajo original publicado en 1954-1955).

Lacan, J. (2008b). El seminario. Libro 20. Aun. Buenos Aires: Paidós. (Trabajo original publicado en 1972-1973).

Lacan, J. (2009). El seminario. Libro 18. De un discurso que no fuera del semblante. Buenos Aires: Paidós. (Trabajo original publicado en 1971).

Lacan, J. (2012). Hablo a las paredes. Buenos Aires: Paidós. (Trabajo original publicado en 1971-1972).

Lombardi, G. (1991). La resistencia como máscara del deseo. Buenos Aires: JVE Psiqué.

Mazzuca, M. (2011). Ecos del pase. Buenos Aires: Letra Viva.

Naparstek, F. (2005). De la espera angustiosa a la serenidad del síntoma o Variaciones sobre la angustia y la espera. Revista Lacaniana de Psicoanálisis, 3, 51-55.

Soler, C. (1988). Finales de análisis. Buenos Aires: Manantial.

Soler, C. (2013). Lacan, lo inconsciente reinventado. Buenos Aires: Amorrortu.

Yacoi, A. (2002). Sueños en la conclusión de los análisis, Mediodichos, 24, 98-101.

Yacoi, A. (2012). Sueño y fin de análisis, una introducción. In L. Ávola, A. Cucagna, 
\& A. Yacoi (Eds.), Brisas clínicas: sueño y final de análisis (pp. 129-133). Buenos Aires: Grama.

\section{Resúmenes}

(Algumas posições subjetivas frente ao impulso nos sonhos)

Este artigo aborda a inserção da pulsão no sonho e a posição do sujeito ante ela. Encontramos três posições diferentes: uma posição defensiva, uma posição mais aberta e uma posição decidida, típica da análise avançada. Os textos freudianos são usados para situar as duas primeiras, e os textos sobre os resultados, da passagem para a terceira. Conclui-se que a análise permite mudar a forma de receber os sonhos, favorecendo outras funções, além de ser "o guarda do dormir".

Palavras-chave: Sonho, pulsão, posição, despertar

(Some subjective positions in view of the drive in dreams)

This paper focuses on the point of insertion of Freudian drive (Trieb) into dreams and the position of the subject towards it. We distinguish three positions: a defensive one, another more open, and a third that is a position of determination, typical of advanced analysis. Freudian texts are used to describe the first two positions, and many texts to describe the passing into the third one. We conclude that the analysis allows changes in the way of receiving our own dreams, favoring other functions besides being "the guardian of sleep".

Keywords: Dream, drive, position, awakening

(Quelques positions subjectives face à la pulsion dans les rêves)

Cet article examine le surgissement de la pulsion dans le rêve et la position du sujet face à celle-ci. Trois positions sont différenciées: une défensive, une autre plus ouverte, et une troisième position, décidée, propre des analyses avancées. Les écrits freudiens sont utilisés pour situer les deux premières et les textes sur les résultats du passage pour la troisième. Nous parvenons à la conclusion que l'analyse permet d'altérer la façon de recevoir les rêves et ainsi de favoriser d'autres fonctions que celle du "gardien du sommeil».

Mots clés: Rêve, pulsion, position, réveil

(Einige subjektive Positionen zum Trieb in Träumen)

Dieser Artikel beschäftigt sich mit der Manifestation des Triebs im Traum und der entsprechenden Positionierung des Subjekts dazu. Es werden drei Positionen unterschieden: eine defensive, eine offenere und eine entschiedene Position, wobei die 


\section{ARTIGOS}

letzte für die fortgeschrittene Analyse typisch ist. Freuds Texte werden als Referenz verwendet, um die ersten zwei in einen Zusammenhang zu stellen und Texte über die Ergebnisse des Überganges um die Dritte zu situieren. Wir kommen zum Schluss, dass die Analyse es ermöglicht, die Art und Weise wie die Träume empfangen werden zu ändern, wobei andere Funktionen begünstigt werden, in Ergänzung zu derjenigen des "Hüters des Schlafes".

Schlüsselwörter: Traum, Trieb, Position, Erwachen

Citação/Citation: Labaronnie, C., \& Lombardi, G. (2018, março). Algunas posiciones subjetivas frente a lo pulsional en los sueños. Revista Latinoamericana de Psicopatologia Fundamental, 21(1), 58-80. http://dx.doi.org/10.1590/1415-4714.2018v21n1p58.5.

Editores do artigo/Editors: Profa. Dra. Ana Maria Rudge e Profa. Dra. Sonia Leite.

Recebido/Received: 8.10.2017/ 10.8.2017 Aceito/Accepted: 15.11.2017 / 11.15.2017

Copyright: (C) 2009 Associação Universitária de Pesquisa em Psicopatologia Fundamental/ University Association for Research in Fundamental Psychopathology. Este é um artigo de livre acesso, que permite uso irrestrito, distribuição e reprodução em qualquer meio, desde que o autor e a fonte sejam citados / This is an open-access article, which permits unrestricted use, distribution, and reproduction in any medium, provided the original authors and sources are credited. 
Financiamento/Funding: Pesquisa financiada pela Secretaria de Ciencia y Técnica da Universidad Nacional de La Plata (Resolução 478/15, período 2015-2018) / Research funded by Secretaria de Ciencia y Técnica da Universidad Nacional de La Plata (Resolution 478/15, períod 2015-2018).

Conflito de interesses/Conflict of interest: Os autores declaram que não há conflito de interesses / The authors have no conflict of interest to declare.

\section{Celeste Labaronnie}

Lic. en Psicología; Becaria de investigación doctoral por la Secretaría de Ciencia y Técnica de la Universidad Nacional de La Plata, Facultad de Psicología (La Plata, Argentina).

Calle 51 entre 123 y 124

Ensenada (CP 1925), Argentina

celelab@gmail.com

\section{Gabriel Lombardi}

Médico y Doctor en Psicología de la Universidade de Buenos Aires - UBA (Buenos Aires, Argentina; Director del Instituto de Investigaciones de la Universidad de Buenos Aires en Psicología; Profesor Titular de Clínica Psicológica de Adultos I, Facultad de Psicología, UBA. Hipólito Yrigoyen 3242

Buenos Aires (CP C1207ABQ), Argentina

gabrielombardi@gmail.com

This is an open-access article, which permits unrestricted use, distribution, and reproduction in any medium for non-commercial purposes provided the original authors and sources are credited. 